\title{
Empirical charges for chemoinformatics applications
}

\author{
Tomáš Bouchal ${ }^{1 *}$, Radka Svobodová Vařeková', Tomáš Raček², Crina-Maria Ionescu', Stanislav Geidl', Aleš Křenek², \\ Jaroslav Koča ${ }^{1}$
}

From 9th German Conference on Chemoinformatics

Fulda, Germany. 10-12 November 2013

Partial atomic charges describe the distribution of electron density in a molecule, and therefore they provide clues regarding the chemical behaviour of molecules. Atomic charges are frequently used in molecular modelling applications such as molecular dynamics, docking, conformational searches, binding site prediction, etc. Recently, partial atomic charges have also become popular chemoinformatics descriptors [1].

Partial atomic charges cannot be determined experimentally, and they are also not quantum mechanical observables. For this reason, many different methods have been developed for their calculation. These charge calculation methods can be divided into two main groups, namely quantum mechanical (QM) approaches and empirical approaches. QM approaches provide accurate charges, but they are very slow and therefore not feasible for large sets of molecules. Empirical charges can be calculated quickly and their accuracy is similar to QM, making empirical charges more appropriate for chemoinformatics applications. A very useful empirical charge calculation method is EEM (Electronegativity Equalization Method) [2,3]. This method provides charges comparable to the QM approach for which the given EEM model was parameterized. The weak point of this empirical method, as well as of other empirical methods, is the necessity for parameterization, and also the insufficient coverage of currently available EEM model parameters.

In our work, we first analysed, how applicable are currently published EEM parameters in chemoinformatics. Specifically, how many molecules from databases of known organic compounds (Pubchem, ZINC, Drugbank

\footnotetext{
* Correspondence: tbouchal@mail.muni.cz

${ }^{1}$ National Centre for Biomolecular Research, Faculty of Science and CEITEC Central European Institute of Technology, Masaryk University, Brno, 625 00, CZ, Czech Republic

Full list of author information is available at the end of the article
}

etc.) they can cover. We found, the coverage is about $50-75 \%$. We would like to show a methodology for preparation of parameters with higher coverage $(>95 \%$ of molecules) and also its results.

\section{Authors' details}

${ }^{1}$ National Centre for Biomolecular Research, Faculty of Science and CEITEC Central European Institute of Technology, Masaryk University, Brno, 625 00,

CZ, Czech Republic. ${ }^{2}$ Institute of Computer Science and Faculty of Informatics, Masaryk University, Brno, 602 00, CZ, Czech Republic.

\section{Published: 11 March 2014}

\section{References}

1. Todeschini R, Consonni V: Molecular descriptors for chemoinformatics. Wiley; 2009.

2. Mortier WJ, Vangenechten K, Gasteiger J: Electronegativity Equalization Application and Parametrization. J Am Chem Soc 1985, 107:829-835.

3. Svobodova Varekova R, Jirouskova Z, Vanek J, Suchomel S, Koca J: Electronegativity equalization method: Parameterization and validation for large sets of organic, organohalogene and organometal molecule. Int J Mol Sci 2007, 8:572-582.

\section{doi:10.1186/1758-2946-6-S1-P60}

Cite this article as: Bouchal et al:: Empirical charges for

chemoinformatics applications. Journal of Cheminformatics 2014

6(Suppl 1):P60.

\section{Publish with ChemistryCentral and every scientist can read your work free of charge \\ "Open access provides opportunities to our colleagues in other parts of the globe, by allowing anyone to view the content free of charge." \\ W. Jeffery Hurst, The Hershey Company.}

- available free of charge to the entire scientific community

- peer reviewed and published immediately upon acceptance

- cited in PubMed and archived on PubMed Central

- yours - you keep the copyright

Submit your manuscript here:

http://www.chemistrycentral.com/manuscript/

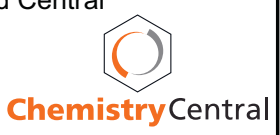

